\title{
Saberes compartilhados: cultura e ciência nas comunidades da Mangueira e UERJ
}

Shared knowledge: culture and science in the communities of Mangueira and UERJ

O presente artigo traz considerações sobre o desenvolvimento do projeto Terra Doce: saberes compartilhados na dinamização da produção em arte e ações ambientais na comunidade feminina mangueirense (ART/UERJ/FAPERJ) no período de agosto de 2009 a junho de 2010. Focando na criação de um espaço de trocas entre duas comunidades femininas, une UERJ e Mangueira numa proposta de educação artística não formal baseada na metodologia da pesquisa-ação ${ }^{1}$.

O projeto Terra Doce integra as ações desenvolvidas pelo projeto extensionista Cerâmicaviva (ART/UERJ/SR3) de atendimento à comunidade fluminense de ceramistas, artesãos e demais interessados na prática e no estudo das artes da cerâmica. É um de seus vetores de pesquisa científica aplicada, parte essencial na integração do tripé acadêmico pesquisa/ensino/extensão. Visa a preservar e dinamizar os acervos artísticos, naturais e socioculturais da Mangueira em seu diálogo com a universidade que, por sua vez, é campo no incentivo à constituição de intervenções na sensibilização e humanização das relações, na superação do ambiente técnico e científico que ali vigora.

As duas comunidades (uerjiana e mangueirense) são ricas em tradições e saberes, entretanto, fechadas em suas próprias redomas epistêmicas e políticas, com extensas barreiras sociais que as mantêm afastadas, o que nos inspirou na geração de envolvimento mútuo por meio da troca de saberes e fazeres, tendo na produção estética feminina em cerâmica o seu laço.

Vizinha à UERJ, a Mangueira é uma comunidade reconhecidamente valorizada em suas formas de memória, arte e histórias de vida. Para os cariocas, Mangueira é uma "instituição", dada a força de sua participação na vida cultural da
Isabela Frade' , Joice Pinto

Henck $^{2}$, Melissa dos Santos ${ }^{3}$

\section{Resumo}

O artigo reflete sobre os procedimentos metodológicos do projeto de arte relacional Terra Doce desenvolvidos a partir da reunião de mulheres artistas de duas comunidades distintas, mas fisicamente próximas, a UERJ e a Mangueira. Objetiva preservar e dinamizar os acervos artísticos, naturais e socioculturais da Mangueira em seu diálogo com a universidade que, por sua vez, é campo no incentivo à constituição de intervenções na sensibilização e humanização das relações, na superação do ambiente técnico e científico a que esse se fecha e reduz. No enlace entre extensão e pesquisa, - laboratório de cerâmica da universidade tornou-se o centro de reunião e discussão de ideias e ambições estéticas, culminando com o coletivo de arte O Círculo de Arte da Terra, seu mais significativo resultado. Entre as ações do grupo são destacadas as mostras de arte, as interferências no campus universitário e os espaços de troca e íntima convivência, envolvendo o compartilhamento de experiências de vida e a prática artística colaborativa.

Palavras-chaves: Arte relacional, Produção feminina, Cerâmica, Comunidade

Área Temática: Cultura Linha de Extensão: Artes visuais, Patrimônio cultural, histórico e natural

'Artista e educadora, doutora em Comunicação pela ECA/USP, docente do PPGARTES/UERJ, Procientista FAPERJ, coordenadora do projeto de extensão Cerâmica Viva UERJ/SR3.

E-mail: isabelafrade@gmail.com

2 Licencianda do Instituto de Artes da UERJ, integrante da equipe do projeto Cerâmica Viva, bolsista PIBIC/CNPQ.

ca Viva, bolsista PIBIC/CNPQ.

${ }^{3}$ Licencianda do Instituto de Artes da UERJ, integrante do Projeto extensionista Cerâmica Viva.

E-mail: melissacsantos@hotmail.com 
cidade. Ambas se postam lado a lado, separadas por uma via expressa, a Radial Oeste. Um efetivo obstáculo que cinde a região, dividindo o território local em dois espaços distintos, dificultando o acesso e a conexão, funcionando como uma linha demarcatória de exclusão. Mesmo com grande proximidade geográfica, a distância social que as separa é grande, havendo pouco ou nenhum fluxo livre e direto entre elas.

A universidade, operando como importante centro de produção científica e cultural, investe em algumas ações politicamente orientadas como abertura em seu nicho de instituição oficial. Alguns projetos acadêmicos estão vinculados a ações de aproximação e reflexão em contato com a sociedade. Entretanto, mesmo em momentos de abertura e dinamismo, como ocorre com o evento anual extensionista UERJ SEM MUROS, poucos são os mangueirenses que atravessam seus portões.

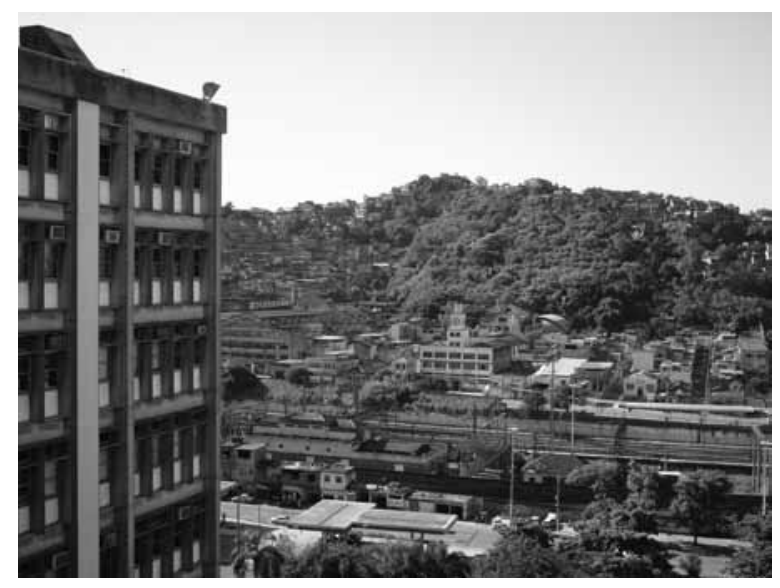

Figura 1 - UERJ-Mangueira

Atento a essa dinâmica, a forma geral do projeto gira em torno do conceito de arte públi$\mathrm{ca}^{2}$, aliando-o ao modelo relacional, dando prioridade ao sentido de compartilhamento e de troca na produção de $\operatorname{arte}^{3}$. Isso ocorre por meio de uma vertente muito clara no que concerne ao papel educativo do projeto, que procura atuar de forma menos diretiva e mais integradora, menos instrucional e mais dinamizadora.

Notadamente voltados para a observação desse fluxo entre culturas, das de lá (Mangueira) e as de cá (UERJ), elaboramos uma proposta de formação de um grupo de compartilhamento e permuta ${ }^{4}$, integrando mulheres desses dois locais com a franca proposição de fazer arte. $\mathrm{O}$ objetivo central calca-se no criar um espaço de entrosamento, de troca e de apoio mútuo entre mulheres, atentando para o fato da estratégica força que as mulheres possuem na favela, como líderes e arrimos familiares e da delicada posição das mulheres-artistas na contemporaneidade, que possuem uma relativa e subordinada entrada nas instituições de arte $^{5}$.

\section{Aproximação para o diálogo entre a Mangueira e a UERJ}

Ao deflagrarmos a aproximação com a comunidade mangueirense, iniciamos um processo de reunião de seus membros, na identificação de mulheres com a disposição para o encontro e para a troca. O primeiro contato teve por objetivo determinar meios de divulgação das ações em proposição pelo projeto Terra Doce. Envolveu a identificação e o contato com instituições que já desenvolvessem trabalhos sociais, artísticos e educacionais voltados para a comunidade mangueirense, como o Centro Cultural Cartola e a Casa das Artes. Isso resultou no estabelecimento de parcerias e na identificação de personalidades e estratégias para a construção de uma primeira ponte entre UERJ e Mangueira.

A dinâmica de pesquisa de campo foi adaptada para as necessidades desse momento, envolvendo visitas aos moradores em suas casas, ambientes de trabalho e estabelecimentos comerciais, espaços de lazer (quadra da Escola de Samba Estação Primeira de Mangueira) e de mobilização social (Associação de Moradores). Durante as visitas, foram realizadas entrevistas informais, objetivando as primeiras imagens e perfis da comunidade, seus personagens, produções culturais e sistemas de valor artístico. Esses diálogos se realizaram levando em conta o objetivo básico de identificar práticas culturais e interesses estéticos locais, os quais estivessem associados a manifestações, objetos e ações cotidianas, muitas vezes marcadas pela invisibilidade ${ }^{6}$.

A busca por saberes e fazeres do dia-a-dia - pelos conhecimentos e domínios culturalmente femininos, reconhecidos e valorizados como tais, muitas vezes fortemente vinculados a fatores e necessidades econômicas - foi adotada como ponto de partida para a constituição de uma concepção não institucionalizada de arte. Com esse intuito, foram visitadas cozinheiras, confeiteiras, manicures, as chamadas "artesãs", donas de casa, 
costureiras, dentre outras personagens femininas da Mangueira, tendo como consequência um processo de imersão nos parâmetros culturais de uma estética corporal feminina própria daquele grupo.

Marcada pelo virtuosismo e precisão nos detalhes, presente na prática da decoração das unhas com formas e figuras variadas, pela exuberância das cores presentes nas roupas, acessórios e maquiagem, puseram-se em contato conjuntos de valores femininos associados à beleza que, algumas vezes, chegariam a divergir da neutralidade (parte da configuração de um espaço acadêmico) nos modos de vestir e falar das mulheres uerjianas diretamente envolvidas na proposta, levando algumas destas a rever a própria imagem feminina?

Esses momentos de deslocamento e imersão foram mediados por personagens locais, atuando como guias para a circulação entre os espaços comunitários e práticas estéticas variadas, mas também para o deslocamento entre os circuitos e as instâncias do poder paralelo local. Funcionaram como uma etapa intermediária à formação de um grupo misto de mulheres e à proposição da realização de encontros regulares entre as mulheres da Mangueira e da UERJ.

A Casa das Artes da Mangueira, mais uma vez, atuou como um espaço de transição e de mediação entre as participantes do grupo, começando um período de encontros semanais que se deram, alternadamente, entre os espaços da ONG, do laboratório de cerâmica da UERJ e também nos espaços institucionais de exposição, como centros culturais e galerias de arte.

\section{As "escolhidas" e seus interesses}

O processo de "escolha" das mulheres partiu da proposta de convite a todas as mulheres que já estivessem envolvidas em atividades de criação estética reconhecidas pela pesquisa de campo para desenvolverem conosco, uerjianas, a produção coletiva em arte. Infelizmente a proposta não chegou a ser efetivamente trabalhada, pois a equipe da ONG, no momento em que iniciaríamos o convite e a apresentação da proposta, informou-nos que já havia feito o processo e que já tinha as "mulheres escolhidas". Não sabemos ao certo como a Casa das Artes realizou a divulgação e a escolha; entretanto, nos apresentaram quinze mulheres interessadas e que iniciaram o projeto conosco. Estas estavam integradas aos quadros do curso de alfabetização noturna para adultos que a ONG iniciava naquele período.

Ao dar início a um diálogo rico e estimulante, elas se mostraram distantes das "artes eruditas" e de todo o circuito que as abrange, referencial das artistas em formação na UERJ, e apresentaram de antemão o propósito de produzir coisas úteis, voltadas para os seus principais e costumeiros afazeres: vasos de cerâmica para a casa, objetos de decoração, adereços. Pensar na arte como necessidade espiritual, intelectual ou emocional era algo que consideravam distante de sua vida. Uma fala constante era: "Por aqui arte tem que ter utilidade, tem que servir para alguma coisa".

Observamos no decorrer da caminhada, entretanto, o desejo, ainda inibido, de algumas mulheres estarem envolvidas com outras expressões artísticas. Especialmente entre as mais novas, adolescentes de 13 e 14 anos, se descortinava a delícia da descoberta da plástica dos materiais e dos processos. Com as mulheres mais maduras, um pouco mais contidas, não foi diferente: o encantamento e a possibilidade de desenvolver outras habilidades, conhecer e trabalhar com outros recursos foi o que as motivou a ingressarem no projeto.

Não podemos deixar de apontar que "as escolhidas" chegaram até nós com uma fala submissa e descrente de seu fazer, refletir e experimentar a arte. No decorrer do processo, todavia, não foi isso que presenciamos na prática. Suas falas de insegurança estavam bem distantes dos resultados que compartilhamos. Uma das mulheres que mais se inferiorizava verbalmente apresentou um despertar artístico na música e na poesia, além da cerâmica, tão forte que nos confessou ter composto uma música para concorrer a hino da torcida na Copa do Mundo e, posteriormente, outra para o busto que havia modelado do mestre sambista Cartola. Devemos confessar que foi um momento de surpresa, encantamento e apreciação de todos, além da certeza de estarmos trabalhando com artistas. $\mathrm{O}$ desejo pela arte se desenvolvia.

O outro grupo de mulheres, ou seja, as artistas graduandas e pesquisadoras da UERJ além daquelas que já frequentavam o laboratório de cerâmica pelo projeto extensionista Cerâmicaviva no Centro Cultural da universidade, desenvolvendo a arte do barro e se interessando pela mesma, não foram selecionadas, escolhidas. São pessoas que 


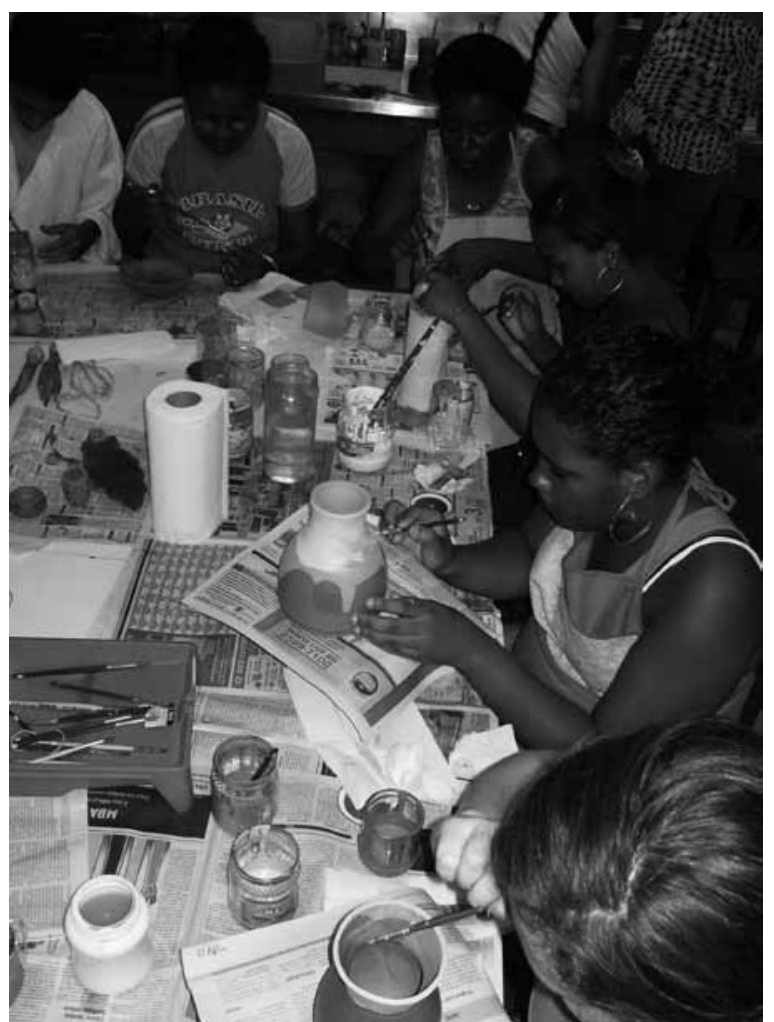

Figura 2 - Ateliê de cerâmica COART/UERJ

se deixaram envolver a partir da apresentação da proposta, acreditando em sua riqueza científica, artística e educacional.

A consolidação da amizade e do elo de conforto e de segurança foi crescendo paralelamente ao corpo da pesquisa, o que possibilitou ao grupo o desabrochar artístico. Algumas mangueirenses perdiam o medo de desaprovação por parte do grupo acadêmico, libertavam-se da coação que constantemente sofriam por residirem na favela e das críticas daqueles que não acreditavam no seu potencial criativo. Essa solidificação foi conquistada com muita aprendizagem de ambas as partes. Nós, acadêmicas, tivemos que analisar o nosso falar e agir para não ofender "as escolhidas". Por mais fortes e lutadoras que se mostrassem, elas apresentavam enorme fragilidade e vulnerabilidade quando uma ação se aproximava, mesmo que sem intenção, a tocar na sua realidade de marginalizadas. E entre as adolescentes estas manifestações características eram gritantes.

\section{Mangueira, de favela à comunidade, apenas mudança de termo?}

O que chama atenção no contexto social da Mangueira é a omissão do termo anteriormente honrado por seus moradores ao afirmarem "eu moro na favela". "Favela" e "favelado" são nomenclaturas que, há algum tempo, incomodam seus moradores, igualadas, assim, a ofensas. É uma terminologia tão negativamente carregada que, em nosso grupo de pesquisa e produção artística, era notório o peso que estes termos traziam.

A vergonha é omitida, ou apenas brevemente aliviada, com a mudança do termo favela e seus derivados, por "comunidade". A substituição dos termos não aliviou, entretanto, a realidade vivenciada por seus moradores, apesar de a palavra comunidade vir carregada positivamente pela sensação de tranquilidade e fraternidade entre seus componentes. Bauman ${ }^{8}$, em seu livro Comunidade, esclarece esse encantamento: "o que essa palavra evoca é tudo aquilo de que sentimos falta e de que precisamos para viver seguros e confiantes". Denomina-o, desse modo, de "paraíso perdido" ou ainda esperado, uma vez que não o conhecemos a partir da nossa própria experiência.

Uma comunidade do sonho de muitos indivíduos ao terem sua perspectiva tornada realidade, sejam eles moradores ou não das favelas, apresenta desvios. Ela "exige lealdade incondicional e trata tudo que ficar aquém de tal lealdade como um ato de imperdoável traição" bem que supomos que a comunidade traga.

As substituições terminológicas vieram apenas passar aos de fora da favela aquela boa imagem que desejam os então moradores, humilhados como "favelados" e que tentam evitar a coerção exercida por aqueles que se sobressaem por suas armas e seus seguidores. Nem sempre uma boa imagem! Na vivência cotidiana, esses indivíduos permanecem em pesadas restrições dada à insegurança e perda da liberdade.

$\mathrm{O}$ viver em comunidade traz consigo uma conformação distinta do sentido que seu termo propõe. Desse modo, o não viver em comunidade significa não ter proteção, estar isolado, desprotegido, mas estar nela apresenta o custo da submissão. "A segurança e a liberdade são dois valores igualmente preciosos e desejados que podem ser bem ou mal equilibrados, mas nunca inteiramente ajustados e sem atrito".

Ao mesmo tempo em que percebemos a queda do isolamento (seja espacial ou de comunicação), aprendemos que é incabível a crença no desaparecimento das fronteiras e estas, por sua 
vez, ressurgem a cada instante. Mike Davis ${ }^{9}$, em Planeta Favela, aponta para o crescimento do isolamento territorial também nas áreas mais abastadas da cidade, citando o desencadear de condomínios fechados, fortemente murados e com vigilância permanente como tentativa de isolamento e segurança.

$\mathrm{Na}$ realidade da vida social, a comunidade - esta unidade homogênea imaginária - é construída por meio de acordos "artificialmente produzidos". A essa construção serve como critério a seleção e a exclusão. O que sobressai nesse quadro, em linhas gerais, entretanto, é que o ajuste não é consequência de acordos e de persuasão entre os componentes para que a unidade exista, mas da repressão dos que se asseguram no poder por via bélica:

A comunidade de entendimento comum, mesmo se alcançada, permanecerá, portanto, frágil e vulnerável, precisando para sempre de vigilância, reforço e defesa. [...] a comunidade realmente existente se parece com uma fortaleza sitiada, continuamente bombardeada por inimigos (muitas vezes invisíveis) de fora e freqüentemente assolada pela discórdia interna $[\ldots]$

É forte o poder dos "donos do morro": os grupos que, ao atuarem em seu cerceamento e domínio, se convertem em formações opressoras.

Foucaul $\mathrm{t}^{10}$, especificamente em seu discurso sobre o poder periférico (micropoder) e o poder central (macropoder, Estado), dá veracidade teórica à nossa vivência de pesquisadores na Mangueira ao fazer entender que o poder não é um objeto que se tem, mas sim uma prática social construída historicamente, permeando todas as relações humanas.

Para apontar o desencadear da relação de poder do tráfico nessa comunidade, é necessário buscar os primeiros movimentos do Comando Vermelho (CV) no presídio Cândido Mendes no Rio de Janeiro. Lá nasceu por um erro do governo, ao encarcerar presos políticos junto a presos comuns. A maior organização criminal já existente no Brasil, estando à frente de dez das principais favelas do Rio de Janeiro - Mangueira, Vidigal, Cantagalo, Maré, Jacarezinho, Pavão Pavãozinho, Providência, Santa Marta e Borel -, é motivação de outras facções como Terceiro Comando (TC) e Amigo dos Amigos (ADA) ${ }^{11}$.
O crime organizado hoje é atingido com o projeto político de intervenção nas favelas, a UPP (Unidade de Polícia Pacificadora), que observamos à distância nas páginas dos jornais diariamente. A UPP ainda não chegou à Mangueira, mas sabemos que muitos moradores desejam essa intervenção pela possibilidade de abertura à condição cidadã. Para nós, hoje, fica, além do postulado teórico, a certeza de que o poder (com esta relação com medo do que está muito próximo) não está centrado no Estado, existem micropoderes que o sustentam e o movimentam.

A visão foucaultiana sobre o poder e suas formas de violência abria nossa compreensão e nos instigava a intervir, e por onde muitas vezes nos transportávamos à favela. A partir das nossas trocas no laboratório de cerâmica, percebemos que o mesmo acontecia com "as escolhidas": um medo constante estava presente em cada uma. Vivenciamos a preocupação com a saída do morro e com a hora de sair do laboratório de cerâmica da UERJ; e algumas falavam da importância de nenhuma mulher estar sozinha para voltar ao lar. Há um "toque de recolher". Apesar dos embates, no momento em que se envolviam e se dedicavam, suas expressões de preocupação e temor se relaxavam, brotando à face olhares curiosos e desejos aventureiros.

\section{As mulheres, suas produções e exposições}

Com o grupo de mulheres mangueirense e dentro da perspectiva da estética relacional obras que se desenvolvem a partir de noções interativas, conviviais e relacionais, "arte que toma como horizonte teórico a esfera das interações humanas e seu contexto social mais do que a afirmação de um espaço simbólico autêntico e privado"3 - criou-se a obra coletiva "Lembrancinhas". Esta obra constitui-se de produções individuais que se abraçaram ao coletivo. Afirma Bourriaud²:

Em outros termos, as obras já não perseguem a meta de formar realidades imaginárias ou utópicas, mas procuram constituir modos de existência ou modelos de ação dentro da realidade existente, qualquer que seja a escala escolhida pelo artista.

Caracterizando-se como uma proposta de "arte relacional", a produção artística "Lembrancinhas" abrangeu aspectos da memória, da 
apropriação e da (re)significação de elementos cotidianos, voltando-se para a "banalidade" dos materiais encontrados aos quais se vinculavam, muitas vezes, relações sobrepostas de usos, fatos, costumes e dimensões afetivas. Ao mesmo tempo, operou sob uma dinâmica processual, baseada na multiplicação da autoria, na troca de experiências e técnicas, no acúmulo e na interação entre objetos, na justaposição e nos jogos compositivos (cromáticos, formais, materiais, entre outros).

Sua realização se baseou em duas ações simultâneas. Uma delas, a produção coletiva de objetos cerâmicos, os quais não se afastaram da atenção conferida pelo grupo a objetos de característica "utilitária", voltando-se para a "categoria" dos potes, obtidos a partir de técnicas variadas de modelagem e tratamento de superfície. Outra, a coleta de sementes e mudas às quais estivessem vinculadas memórias dos participantes relacionadas a lugares, pessoas, episódios, textos e crenças, por exemplo, da experiência cotidiana de cada integrante do grupo.

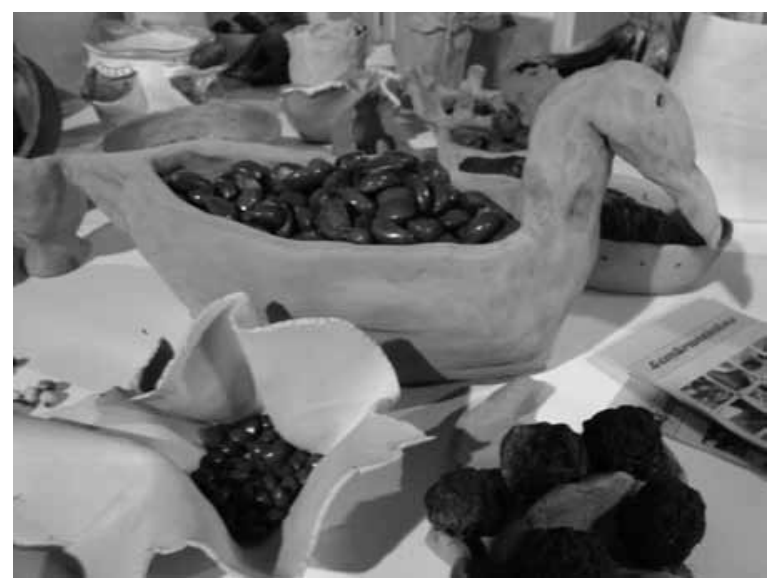

Figura 3 - Trecho da obra coletiva

"Lembrancinhas" na exposição Terra Doce no Centro Cultural Cartola

Nessa primeira proposta de criação coletiva consolidaram-se as dinâmicas de troca e diálogo entre os dois grupos abrangidos pelo projeto Terra Doce, que se baseou na partilha de técnicas de manipulação e modelagem, não se limitando a um processo unilateral de transmissão de normas e procedimentos por parte da equipe de ceramistas vinculada ao projeto visando a algum tipo de "formação técnica". Estruturou-se a partir de uma via de mão dupla, na qual modos de fazer foram identificados, adaptados e transmitidos por parte de todos os integrantes do grupo. Muitas vezes es- tes processos estavam vinculados a experiências domésticas ou da infância, envolvendo gestos e práticas do dia-a-dia (como os de amassar, misturar, sovar e cortar) que se encontram (re)significados e (re)trabalhados na dinâmica criativa.

O processo de constituição da obra "Lembrancinhas" também abriu um espaço de acolhimento para a troca de narrativas pessoais, abordando aspectos da memória coletiva ${ }^{14}$ de cada participante. Seu ponto de partida era a materialidade da argila e suas evocações para cada participante, estabelecendo um campo de convivência permeado por uma experimentação direta, na qual experiências estéticas, poéticas, utilitárias e lúdicas, entre outras, com o barro compuseram o primeiro "círculo" de convivência do projeto. Este "círculo" de narrativas foi, então, ampliado pela dinâmica de coleta de sementes e mudas, a qual expandiu a prática do diálogo dos limites do laboratório e as ações nele contidas para outro campo e outros espaços, espaços do dia-a-dia, externos e cotidianos, nos quais circulam outras relações, outras narrativas e outras memórias.

$\mathrm{Na}$ interação entre potes e sementes observamos a concretização e permanência das memórias. As memórias da coleta e do fazer transformaram o conjunto de objetos cerâmicos e sementes em um grande mapa afetivo no qual se presentificaram várias localidades do Rio de Janeiro. Através dos relatos de cada mulher do grupo, estabelecendo-se um jogo entre presença e ausência no qual, ao mesmo tempo, se faziam materializadas, "Lembrancinhas" atingia a dimensão de um grande livro de narrativas e memórias ${ }^{4}$. De certo modo, estes desdobramentos dialogaram com a ânsia manifesta por parte das mangueirenses desde os primeiros diálogos entre os grupos para que as atividades no projeto de algum modo contribuíssem para o aprendizado da leitura e da escrita (lembramos que o grupo foi originalmente composto por mulheres integrantes dos cursos noturnos de alfabetização de adultos mantidos pela Casa das Artes da Mangueira).

No decorrer, ocorriam novas adesões: outras mulheres iam sendo convidadas a ingressarem no grupo, convite feito pelas próprias participantes. Algumas mulheres levaram suas amigas, parentes, filhos. Houve, nesse sentido, um momento peculiar: a discussão sobre deixar aberta ou não a participação de homens, pois alguns convidados es- 
tiveram participando das atividades. Descolava-se então a discussão do gênero daquele sexo, isto é, de como as questões do feminino atingiam a todos, homens e mulheres ${ }^{16,7}$. Algumas precisavam ir aos encontros com seus filhos, o que o grupo atentamente atendeu, compondo uma ação conjunta num grupo então menos homogêneo, composto não apenas de mulheres, mas de suas pessoas mais próximas.

Oscilando entre 15 a 25 participantes, quando sentida essa dificuldade de muitos da Mangueira no deslocamento e integração ao grupo que atuava no laboratório de cerâmica, o grupo prosseguia animadamente no projeto de constituição de uma ação estético-política de envolvimento entre as duas comunidades. A possibilidade de criarem os laços entre ambas era o principal objetivo, em que cabem ser destacadas as posições assumidas pelas artistas universitárias. A dificuldade de entendimento de outro modo de vida e de consciência estética, talvez dada a imaturidade presente entre essas participantes da universidade, foi paulatinamente flexibilizada com longas e duradouras conversas entre todas as integrantes, tecidas durante os momentos da prática no laboratório. O fazer se prestava assim, também, de certa forma, a um percurso para outra realidade, uma possibilidade de atravessamento para outro modo de ser e estar no mundo.

Uma oportunidade única surgiu no momento em que escolhíamos as cores para a finalização dos objetos "Lembrancinhas", quando decidimos pelos diferentes tons de rosa e verde, na caracterização de uma estética francamente "mangueirense". As combinações contrastantes entre os tons, escolha calcada na identidade local, observada pela pintura das casas e nas cores das roupas dos moradores, em franco orgulho de sua escola de samba, foram transpostas para a superfície dos objetos em jogos cromáticos, os mais variados possíveis. A peculiar elegância monocromática das artistas universitárias foi percebida após a primeira sessão de pintura, observada a produção e comentados seus efeitos. A mescla de atitudes entre a composição pujante de um colorido mais popular se fazia contrastar com a economia cromática daquelas.

A consciência de estarmos abrindo para novos procedimentos, criando elos entre uma concepção erudita de arte e uma estética popular, foi sendo apreciada como um recurso e um desafio para a ampliação do repertório do grupo. A prática artística de um coletivo criava essa dinâmica das trocas e interferências constantes.

A apreciação de exposições e a própria oportunidade de expor, momento este de abertura do sentido social do trabalho de artista, fizeram-se presentes no projeto. A obra "Lembrancinhas" foi exposta no coletivo Corpoartelabor, realizado em setembro de 2009 no CEDIM / Centro - Espaço Cultural Heloneida Studart, na 20 ${ }^{a}$ UERJ sem muros em outubro de 2009, e na própria comunidade, na coletiva Terra Doce no Centro Cultural Cartola, em dezembro do mesmo ano. Todos do projeto estiveram presentes nos processos decisivos para que as exposições fossem concretizadas. Sua realização foi um momento de alegria e de mais uma conquista para todas as mulheres. A proposta da venda de trabalhos se deu ainda de modo experimental, provocada pela ideia de tornar essa relação com o público e também como troca econômica.

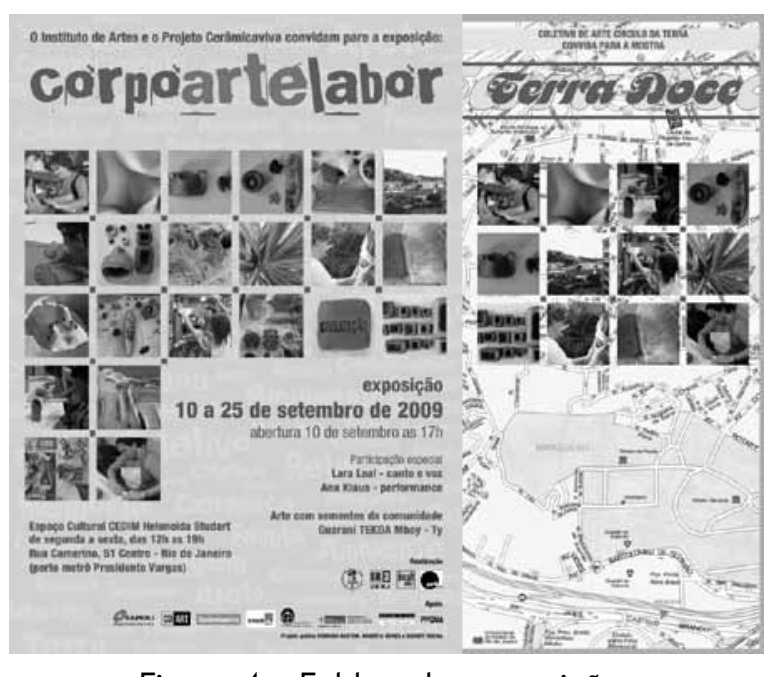

Figura 4 - Folders das exposições Corpoartelabor e Terra Doce

\section{Considerações finais}

Este artigo, baseado na análise do desenvolvimento da proposta de educação artística não formal, buscou chamar a atenção para a necessária troca dos saberes e fazeres na organização de núcleos geradores que viabilizem a produção de formas de arte comunitariamente integradas. $\mathrm{O}$ projeto constituiu formas experimentais de divulgação e comercialização com vistas a gerar melhores condições de trabalho e geração de renda de modo sustentável, fomentando um espaço neutro, para além 
das travessias, resultado desse encontro entre os participantes na prática de amparo e apoio mútuo.

Constatamos, a partir dessas práticas e pesquisas, que o envolvimento e a contribuição de cada uma das mulheres, sejam elas da Mangueira ou da UERJ, foi o solo necessário para a construção consistente de um projeto criativo e com uma multiplicidade de linguagens. A formação e os encontros do grupo de pesquisa e produção em arte - além do efetivo atravessamento científico e cultural entre as participantes das duas comunidades - encaminham os integrantes deste para a consolidação do nosso principal objetivo: a formação de O Círculo de Arte da Terra, ou O Círculo.

$\mathrm{Na}$ dinamização da troca entre as participantes e divulgação do projeto para além dos encontros no laboratório de cerâmica na COART/ UERJ, criaram-se como estratégia educativa o blog http://terradoceuerj.wordpress.com/ e o Orkut Terra Doce. Como próximo passo, o grupo propôs a criação de um álbum virtual contendo fotos da produção em cerâmica, dos encontros dentro e fora do laboratório, das exposições realizadas e visitadas, entre outras, para o livre acesso de todos.

Por fim, a relevância do projeto, não só para o mundo acadêmico, mas também para o circuito de arte, foi confirmada a partir dos reflexos da última exposição realizada pelo grupo Artes da Terra: gênero, identidade e cultura de 19 de abril a 21 de maio de 2010 - Galeria Gustavo Schnoor, COART, UERJ - e do convite e propostas externas para outras mostras (Centro Cultural em Nova Iguaçu, MAQUINHO - Anexo socioeducativo MAC Niterói - e Espaço Imaginário/RJ) recebidas pelo Círculo e que se apresentam como potenciais espaços de reverberação do trabalho realizado.

\section{Referências}

1.THIOLLENT, Michel. Metodologia da Pesquisa-ação. $3^{a}$ ed. São Paulo: Cortez, 1985. 132 p.

2. SILVA, Fernando Pedro. Arte Pública -diálogo com as comunidades. Belo Horizonte: Editora C/ Arte, 2005.

3.BOURRIAUD, Nicolas. Estética Relacional. São Paulo: Martins Fontes, 2009. 152 p.

4. RANCIÉRE, J. A Partilha do Sensível. São Paulo: Editora 34, 2005. 72 p.

5. FRADE, I. El Círculo de Mujeres en el Arte de la Tierra: por la activación de la producción plástica en la comunidad feminina en Mangueira. Anais CLEA
Congresso Latino Americano e Caribenho de Arte Educação, 2009. Disponível em: http://www.cleabrasil.com.br/grupo/GRUPO\%209\%20VERDE

6. UPITIS, Rena. As artes perdidas. Revista Profissão Docente, Uberaba, v. 9, n. 19, p. 1-15. 2009.

7. TOURAINE, Alain. O Mundo das Mulheres. Trad. Francisco Moras. Petrópolis: Editora Vozes, 2007. 208 p.

8. BAUMAN, Z. Comunidade. Rio de Janeiro: Zahar Editores, 2003. 144 p.

9. DAVIS, Mike. Planeta Favela. São Paulo: Boitempo editorial, 2006. $272 \mathrm{p}$.

10. FOUCAULT, Michel. Microfísica do poder. $10^{\circ}$ ed. Rio de Janeiro: Graal, 1992. 295 p.

11. CYPRIANO, André. André Cypriano e as favelas brasileiras. Revista Zupi - Arte, Design e Moda. Rio de Janeiro, 7.ed., p. 21-29, nov.2007.

12. POLLAK, Michael. Memória e Identidade Social. Revista Estudos Históricos, Rio de Janeiro, v. 5, n. 10, p.200-215. 1992.

13. STEARNS, Peter N. História das relações de gênero. Tradução de Mirna Pinsky. São Paulo: Contexto: $2007.256 \mathrm{p}$.
Abstract
The article analyzes the methodological proce- dures of the relational art project Terra Doce developed by gathering female artists from two different but close communities, UERJ and Mangueira. It aims to preserve and promote Mangueira's artistic, natural and socio-cultural heritage in its dialogue with the university, whi- ch, in turn, encourages the interventions for relationships awareness and humanization, to transcend the technical and scientific envi- ronment enclosing and reducing it. As link be- tween extension and research, the university's ceramics laboratory became the center for meetings and discussing ideas and aesthetic ambitions, culminating with the art collective $\mathrm{O}$ Círculo de Arte da Terra, its most significant re- sult. The group's efforts include the art shows, the interferences in the university campus and the exchange and intimate living spaces, invol- ving sharing life experiences and collaborative art practices.
Keywords: Relacional art; Female production; Ceramics; Community 